\title{
Estimating Direct Runoff from Storm Rainfall Using NRCS Runoff Method and GIS Mapping in Vientiane City, Laos
}

\author{
Vannasy M. ${ }^{1, *}$ and Nakagoshi N. ${ }^{1}$ \\ ${ }^{1}$ Graduate School for International Development and Cooperation, \\ Hiroshima University, Hiroshima, Japan \\ *moukmany.not@gmail.com
}

\begin{abstract}
The amount of direct runoff present in a watershed indicates the hydrological condition of the area, reflecting the characteristics of land use, soil and rainfall distribution. This study aims to measure the hydrological condition of Vientiane city by examining the runoff potential. This study obtained direct runoff from storm rainfall for the city area which covered the Mark-Hiao River watershed. The rainfall-runoff calculation is useful for future design of drainage networks within a watershed to support flooding management. The Geographical Information System (GIS) software is the main technology used in this study for the purposes of assigning the estimating process, watershed delineation, extracting hydrologic parameters and mapping. There are two main parts discussed with useful results in this study, delineating the river watershed and estimating weighted direct runoff for a watershed area. The result of delineating river watershed process, showing the changing elevation data achieved by combining the two elevation data, Shuttle Radar Topography Mission 30m Digital Elevation Model (STRM $30 \mathrm{~m}$ DEM), and digital contour data (Vientiane database), performed well in terms of representing surface flow networks and their topography. The calculated average of direct runoff in each small sub-watershed estimated by using Weigh-Q method of the National Resources Conservation Service (NRCS) very well showed the poor to good hydrologic condition in each specific area in 1-to5-day durations of storm events.
\end{abstract}

Keywords: NRCS runoff method; watershed; direct runoff; storm rainfall; land use; soil textures; GIS

\section{Introduction}

The calculation of the response characteristics of a watershed from runoff values under specific rainfall conditions is a fundamental method in the study of the hydrological characteristics of river watersheds. It is also an important type of analysis for watershed development and management. The response characteristics indicate which areas in river basin have poor or/and good hydrologic conditions, where a good condition is an area that has low runoff potential, while a poor condition has a high runoff potential [1]. There are several methods or approaches to estimate runoff and the transformation process of rainfall to runoff. The most widely used is the method proposed by National Resources Conservation Service Curve Number (NRCS-CN) because of its flexibility and simplicity [2]. The NRCS method of estimating runoff from storm rainfall was developed and described in Chapter 10 of the updated National Engineering Handbook, part 630 (NEH630) [3], which described clearly information for parameters related to rainfall-runoff relation, and were illustrated using examples for application of the method.

Rainfall depth is not the sole determinant of the amount of runoff for a watershed. Runoff depth is further affected by many parameters as depicted by the curve number simulation with hydrologic soil-cover complex. Chapter 9 of NEH-630provides variability in curve number $(\mathrm{CN})$ with different conditions, called Antecedent Runoff 
Conditions (ARCs) which are divided into three classes: I for dry conditions (ARCI), II for average condition (ARCII), and III for wetter conditions (ARCIII). These ARC classes are divided according to the rainfall intensity and duration, total rainfall, soil moisture conditions, cover density, stage of growth, and temperature [3].To see multiple possibility of runoff amount occurring in the study site, the three $\mathrm{CN}$ variabilities were considered in this study as well.

The Digital Elevation Model (DEM) provides important inputs of hydrological modelling and analysis that are crucial in developing the data for watershed delineation of a river basin. The DEMs can automatically extract basin geometry, stream network, slope, flow direction, etc., which have three schemes of structuring elevation data namely triangulated irregular networks (TIN), grid network which is the most widely used data structure, and the vector or contour based network [4]. The quality of DEM data directly affects the watershed hydrological modelling. However, there are many cases of errors in DEM, such as insufficient and missing data in some regions, due to the presence of water or other interference [5]. DEM data from Shuttle Radar Topography Mission (SRTM) is a free dataset available for global topographic imaging that performs well for modelling hydrological analysis. Differences between SRTM-derived DEMs and from other sources when working on hydrological modelling and analysis were found. To compensate, an interpolative technique was used to fill in missing data that very well represented the hydrological characteristics of a catchment [6].

In response to such errors in DEM data in terms of watershed hydrological modelling of stream networks, determining the potential location and presenting topographic characteristic, two different datasets are examined. The datasets are one from national database and others from global DEM dataset with 30 maters solution downloaded from SRTM. The main purpose of using both datasets is to locate sites and generate basin areas and watershed boundaries of Mark-Hioa River.

The present study focuses on developing data, especially DEM datasets, for river watershed delineation purpose. Data on land use/soil cover, hydrological soil group and daily rainfall were prepared for direct runoff estimation from storm rainfall in different conditions. These conditions are ARCI, ARCII and ARCIII which were set using NRCS methodology. These parameters were used to characterize hydrologic conditions from runoff value of Mark-Hiao River watershed. The results of the database development process, i.e., delineating watershed area, estimating runoff, were explained by mapping using ArcGIS.

\section{Study Erea and the Data Sets}

\subsection{Study Area}

The Mark-Hiao watershed was selected for the present study because different types of datasets are available for this area. The Mark-Hiao River and its drainage systems, with a length of about $30 \mathrm{~km}$, flows into the Mekong River at the drainage gate. The river lies between $102^{\circ} 35^{\prime}$ to $103^{\circ} 55^{\prime} \mathrm{E}$ longitude and $17^{\circ} 57^{\prime}$ to $18^{\circ} 03^{\prime} \mathrm{N}$ latitude. The Mark-Hiao River functions as storage of rainwater and waste water for the urban area of Vientiane city. This area includes a part of the city center of Vientiane City and a range of land cover types including agricultural areas, marsh and swamp areas, forested areas, and urbanized areas. In recent years, the built-up areas have increased rapidly which in turn have caused a decrease in forested and vacant areas [7]. The location and characteristic of Mark-Hiao River for the study area are shown in Figure 1.

\subsection{Data Sets}

There were three digital datasets analyzed in this study which were obtained from three different organizations in Laos. These data were the urban land use dataset of 2010 
(Figure 2) observed and classified by Public Works and Transport Institution, the 2010 soil characteristics dataset (Figure 3) developed and approved by Ministry of Agriculture and Forestry, and the contour line data of 1980-1990 (Figure 4) from National Geographic Department.

The rainfall dataset available is the daily rainfall record from 1982-2014, with a total average annual rainfall of $1,661 \mathrm{~mm}$ at Vientiane Rainfall station (located at $17^{\circ} 58^{\prime} 0^{\prime \prime} \mathrm{N}$, latitude and $102^{\circ} 36^{\prime} 0^{\prime \prime}$ E longitude) obtained from Department of Meteorology and Hydrology (DMH). It is the only rainfall station in the area.

Since DEM dataset is necessary to extract flow direction, steam networks, and other topographic variables to obtain the shape of a watershed area, it is important to examine carefully the quality of the DEM to be used. In this study, two DEM datasets, one obtained from digital contour line dataset (a national dataset), and the other from SRTM DEM (Figure 5) (a download dataset), were examined to find out suitable dataset for the study area. The national dataset represents the current photograph showing the bodies of water and the downloaded dataset represents the flow direction with its stream networks.

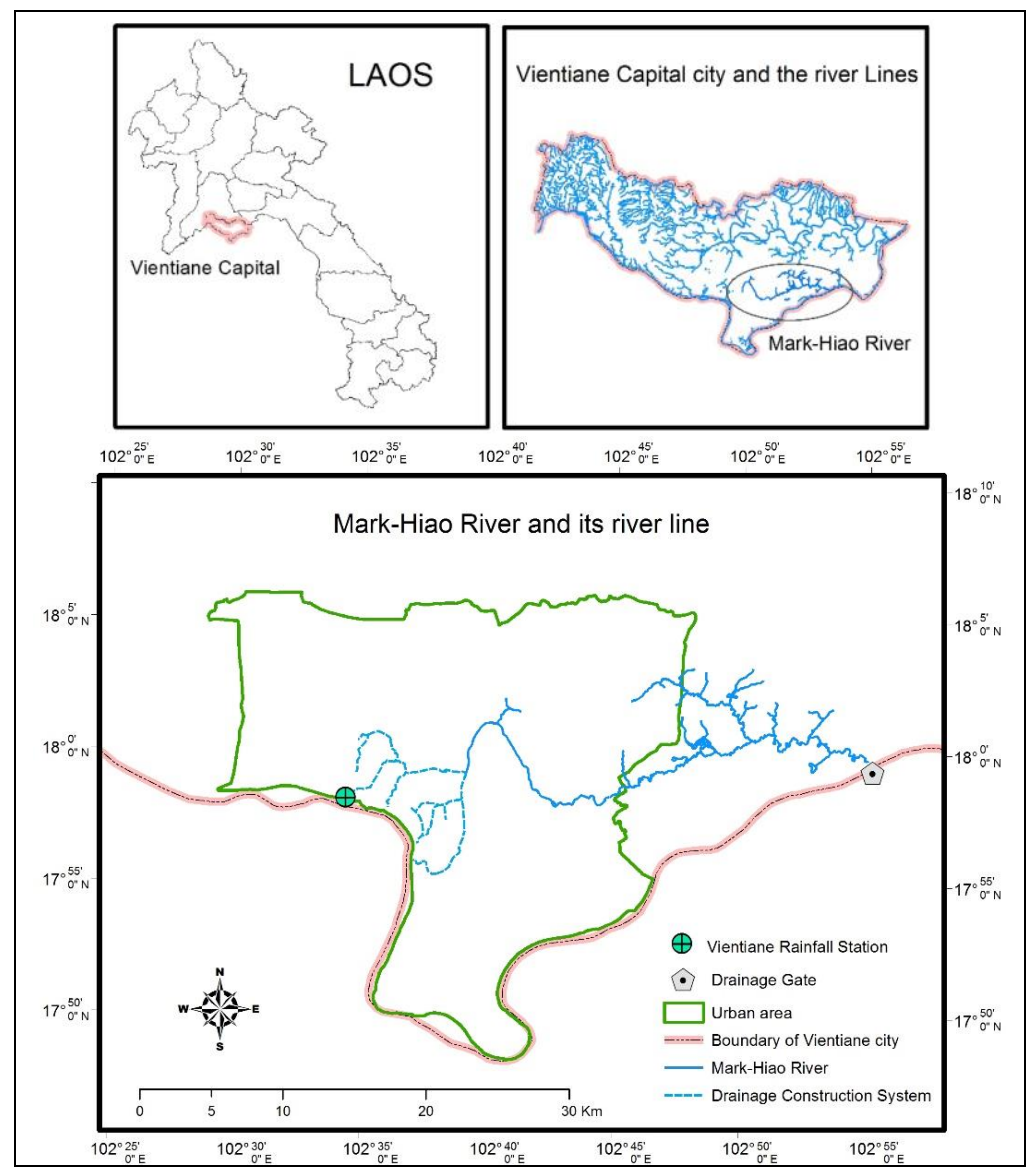

Figure 1. Map of the Study Area showing the Location of Mark-Hiao River, Vientiane City 


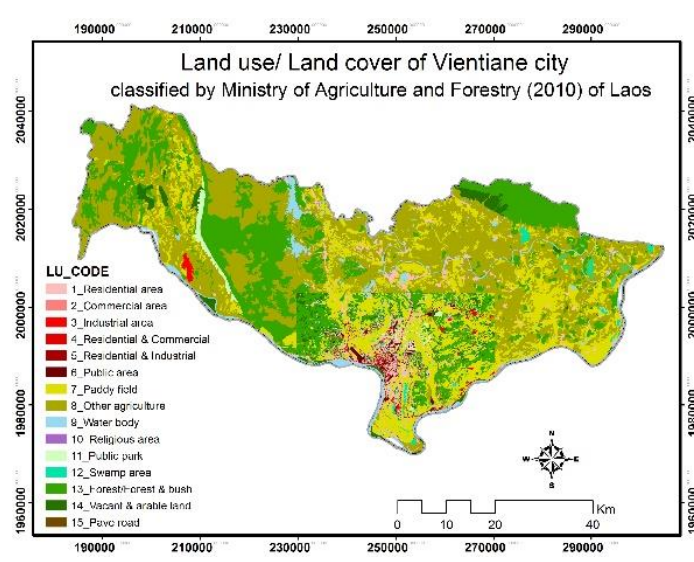

Figure 2. Digital Dataset of Land use/Land cover of Vientiane City

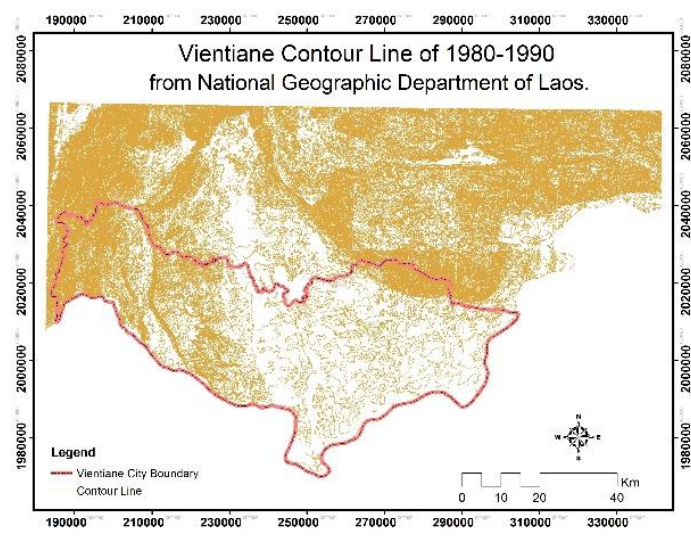

\section{Figure 4. Digital Dataset of Contour Line of Vientiane City}

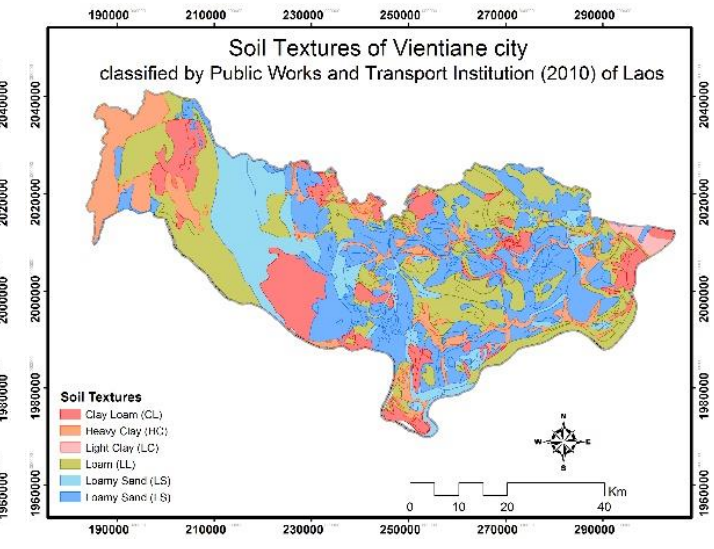

Figure 3. Digital Dataset of Soil Texture of Vientiane City

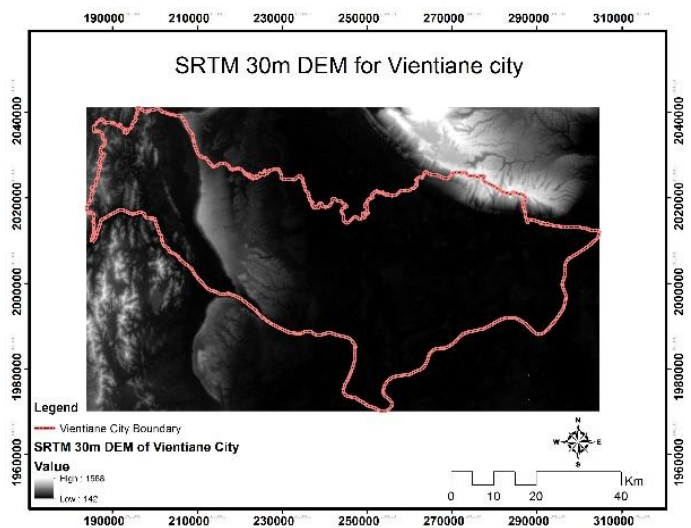

Figure 5. STRM 30m DEM Dataset for Vientiane City

\section{Materials and Methods}

The data was processed in three main parts; data development, hydrological calculation and data presentation. For the data development, four main factors were developed, (1) DEM data to delineate the shape of the area of the river watershed, as well as the average slope, flow direction and drainage network within the watershed, (2) soil textures and its hydrological soil groups (HSG) classification, (3) land use classification data where land use and the HSG classifications were used in defining hydrologic soil-cover complexes for assessing $\mathrm{CN}$ values, and (4) daily rainfall dataset to estimate storm events as an input data to test the response characteristic of specific storm conditions in the watershed. The hydrological calculation was estimated based on NRCS runoff method [3]. For the data presentation, ArcGIS (version 10.2.2) was used for modelling and mapping purposes. Figure 6 shows the procedure of the analysis of direct runoff for this study. 


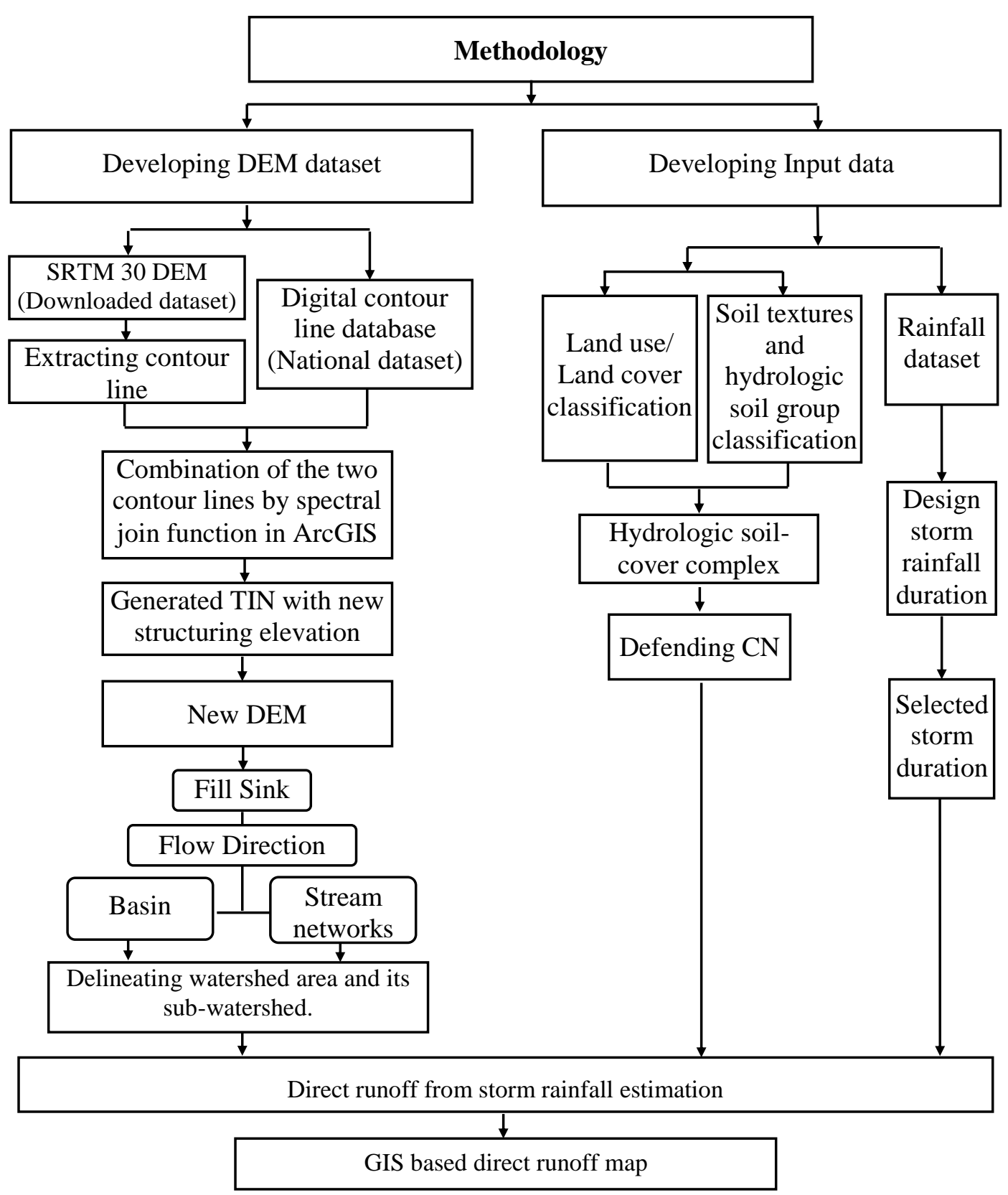

Figure 6. Methodology for the Direct Runoff Estimation

\subsection{Development of DEM Dataset for Watershed Delineation}

The shape of the watershed area was delineated based on data of DEM flow direction, and then the watershed boundary was defined following the flow direction grid or cell. To obtain the flow direction which can represent current characteristics such as river body or stream line and slope condition, DEM from different sources might be good to examine, or/and interpolative technique for filling in missing/error data from selected DEM might be necessary.

As mentioned before, two DEM datasets from different sources were used for this study, namely DEM obtained from contour line dataset and SRTM 30m DEM. Both datasets were examined when delineating the river watershed for checking mainly the flow direction and the stream network that are suitable for representing Mark-Hiao river line. The result of the primary examination showed that the shapes were similar but with a 
difference of about $11.75 \mathrm{~km}^{2}$ in the total area. However, they were found to be completely different in terms of hydrological characteristics. The most noticeable point is when comparing the river line, the downloaded data has an error at the point where the stream line should be connected, whereas the digital contour cannot clearly present flow direction and its stream network (Figure 7). Thus, to obtain the final shape area for the study site both DEM datasets were applied. This was to interpolate and adapt the downloaded data to the existing digital Lao database dataset, and the change of elevation characteristics or slope conditions might represent more closely the actual condition of the watershed characteristic.

To complete the analysis, three main things were done. The first was preparing contour line data from the downloaded SRTM data by extracting contour lines with interval distance of "10", and using the digital contour lines from the Vientiane database which have elevations ranging from 160 to 220 with distance of " 10 ". The second step was joining the two digital contour lines by using the 'spatial join' function in GIS Analysis tools, and setting the digital contour line of SRTM to be the target feature when running the process. The new slope condition was applied in this process. The last part was generating a triangulated irregular network (TIN) from the new dataset and the new DEM-based contour derived from the TIN dataset. The results of the new DEM-based contour dataset were introduced into the watershed delineating process through the Arc Hydro tool in ArcGIS.

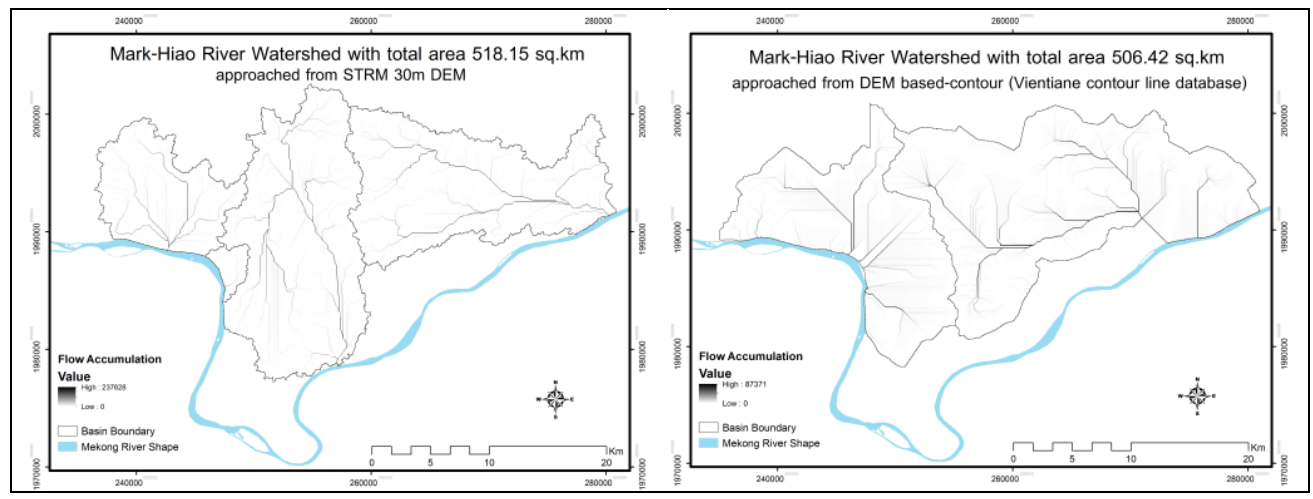

Figure 7. Showing the difference characteristic of the river watershed approached from the two different DEM data sets

\subsection{Soil Textures and Hydrologic Soil Group Classification}

Soil texture is an important factor to determine infiltration rate of water entering into the soil surface. It is the water transmission rate within the soil texture types which are classified into sand, silt and clay. The transmission rate was defined into Hydrologic Soil Group (HSG). Table 1 describes the transmission rate for each HSG definition [3], and based on the digital soil texture database (Figure 3), the left-side column of the table shows the six types of soil texture found in related area which were used for HSG classification for further processing.

\subsection{Land Use and Cover Type}

Land use database of Vientiane city which was classified into fifteen types (Figure 2) was reclassified into cover types or treatment classes such as open space, impervious, water and residential area, etc. The cover treatments were combined to classified hydrologic soil group in Table 1 to identify specific $\mathrm{CN}$ value in each related area. Chapter 9 of NEH 630 [3] provides the standard table and graphs for such $\mathrm{CN}$ values. 
Table 1. The Hydrologic Soil Group, Definitions and Soil Textures of the Study Area

\begin{tabular}{|l|l|l|l|}
\hline HSG & \multicolumn{1}{|c|}{ Soil Texture } & \multicolumn{1}{|c|}{$\begin{array}{c}\text { HSG definitions } \\
\text { (USDA-NRCS,1986) }\end{array}$} & $\begin{array}{c}\text { The six types of soil } \\
\text { textures in study area }\end{array}$ \\
\hline A & $\begin{array}{l}\text { Sand, loamy sand, } \\
\text { or sandy loam }\end{array}$ & $\begin{array}{l}\text { Low runoff potential and high } \\
\text { infiltration rates; This soils have } \\
\text { high rate of water transmission } \\
\text { (greater than 7.62 } \mathrm{mm} / \mathrm{hr} \text { ) }\end{array}$ & $\begin{array}{l}\text { (1) Loamy Sand (LS) } \\
\text { (2) Sandy Loam (SL) }\end{array}$ \\
\hline B & Silt loam or loam & $\begin{array}{l}\text { Moderate infiltration rates; The } \\
\text { soils have moderate rate of eater } \\
\text { transmission }(3.81 \mathrm{~mm} / \mathrm{hr} \text { ) }\end{array}$ & (3) Loam (LL) \\
\hline C & Sandy clay loam & $\begin{array}{l}\text { Low infiltration rates; The soils } \\
\text { have a low rate of water } \\
\text { transmission }(1.27-3.81 \mathrm{~mm} / \mathrm{hr})\end{array}$ & \\
\hline D & $\begin{array}{l}\text { Clay loam, silty clay } \\
\text { loam, sandy clay, } \\
\text { silty clay, or clay }\end{array}$ & $\begin{array}{l}\text { High runoff potential; These } \\
\text { soils have very low rate of water } \\
\text { transmission (0-1.27 } \mathrm{mm} / \mathrm{hr} \text { ) }\end{array}$ & $\begin{array}{l}\text { (4) Clay Loam (CL) } \\
\text { (5) Heavy Clay (HC) } \\
\text { (6) Light Clay (LC) }\end{array}$ \\
\hline
\end{tabular}

\subsection{Maximum Rainfall Data}

Rainfall data was used to design single rainfall event as input data into runoff estimation. The annual maximum rainfall for 33 years (1982-2014) at Vientiane station was used to design storm rainfall duration in the continuously events from 1, 2, 3, 4 and 5 days. In order to assist in the rainfall analysis on storm events, the method of Average Recurrence Interval (ARI) was used to measure exceedance possibility of rainfall event in the last 33 years. The regression analysis for this study was carried out on the relationship between the events of 1-, 2-, 3-, 4- and 5-day and the average return interval in year of those events were conducted.

\subsection{Runoff Estimation}

Estimating the runoff in this study was based on the NRCS runoff method which was developed to estimate total storm runoff from storm rainfall presented in NEH-360 [3]. In terms of curve number $(\mathrm{CN})$, variability was assessed for all three classifications of ARC: ARC I for dry conditions, ARC II for average conditions and ARC III for wet conditions.

The NRCS runoff method equation is:

$$
Q=\frac{\left(P-I_{a}\right)^{2}}{\left(P-I_{a}\right)+S} \quad P>I_{a}
$$

Where $Q$ is runoff (mm), $P$ is rainfall (mm), $S$ is potential maximum retention after runoff begins $(\mathrm{mm})$ and $I_{a}$ is initial abstraction $(\mathrm{mm})$.

And when $I_{a}=0.2 \mathrm{~S}$, equation 1 gives:

$$
Q=\frac{(P-0.2 S)^{2}}{(P+0.8 S)}
$$

And potential maximum retention (S) was determined using an equation related to $\mathrm{CN}$ as follows:

$$
S=\frac{25400}{C N}-254
$$


The direct runoff from the average runoff for the whole watershed which has multiple hydrologic soil-cover complexes in watershed area was estimated by using the method of weighted runoff (weighted-Q method). The Weighted-Q was calculated using equation 4.

$$
\text { Weighed } Q=\frac{\sum Q_{i} A_{i}}{A}
$$

Where, $Q_{i}$ is the runoff value for each complex for individual hydrologic soil-cover, $A_{i}$ is related area presented in each complex; and A is the total watershed area.

\section{Results and Discussion}

\subsection{Watershed Delineation}

Based on the results of generated river watershed by interpolative technique of changing elevation data approved by combining the two elevation datasets, the expected connection points of a stream network was completed successfully. When it was applied to Mark-Hiao river line (Figure 1), the stream line network appeared in the watershed area was almost close to the river line. The total area of the study site was $505.76 \mathrm{~km} 2$. Figure 8 shows the digital datasets, output figures, and the watershed generation process for the Mark-Hiao River basin. For modelling purpose, the generated watershed was delineated into 43 sub-watersheds (Figure 9) which were generated based on an automatically delineating process in ArcHydro tool.

\subsection{Hydrologic Soil-cover Complex}

The hydrologic soil-cover complex was derived from the combination of hydrologic soil group (Figure 10) and land use and treatment classes or cover types (Figure 11). Each complex has a specific runoff curve number $(\mathrm{CN})$ which indicates the runoff potential. CNs for such complexes for the study area were identified based on the standard table of NEH-360 [3]. As a result of the reclassification and combination, hydrologic soil-cover complexes for the study area were defined into nine (9) complexes with its specific CN values for hydrologic soil groups A, B and D as shown in Table 2.

\subsection{Design Storm Rainfall}

The average river interval of continuous durations, 1-to-5-day storm events, was carried out for rainfall analysis. Figure 12 shows the trend lines of regression analysis, while Table 3 shows the ARI of storm events in tabular form for selected rainfall duration. The storm rainfall duration data of 1- to 5-day events over a 25-year period were selected for rainfall-runoff distribution. Another thing to notice was that the rainfall amount for each duration was supposed to spread as the same amount for over the watershed area when assessing direct runoff calculation. 


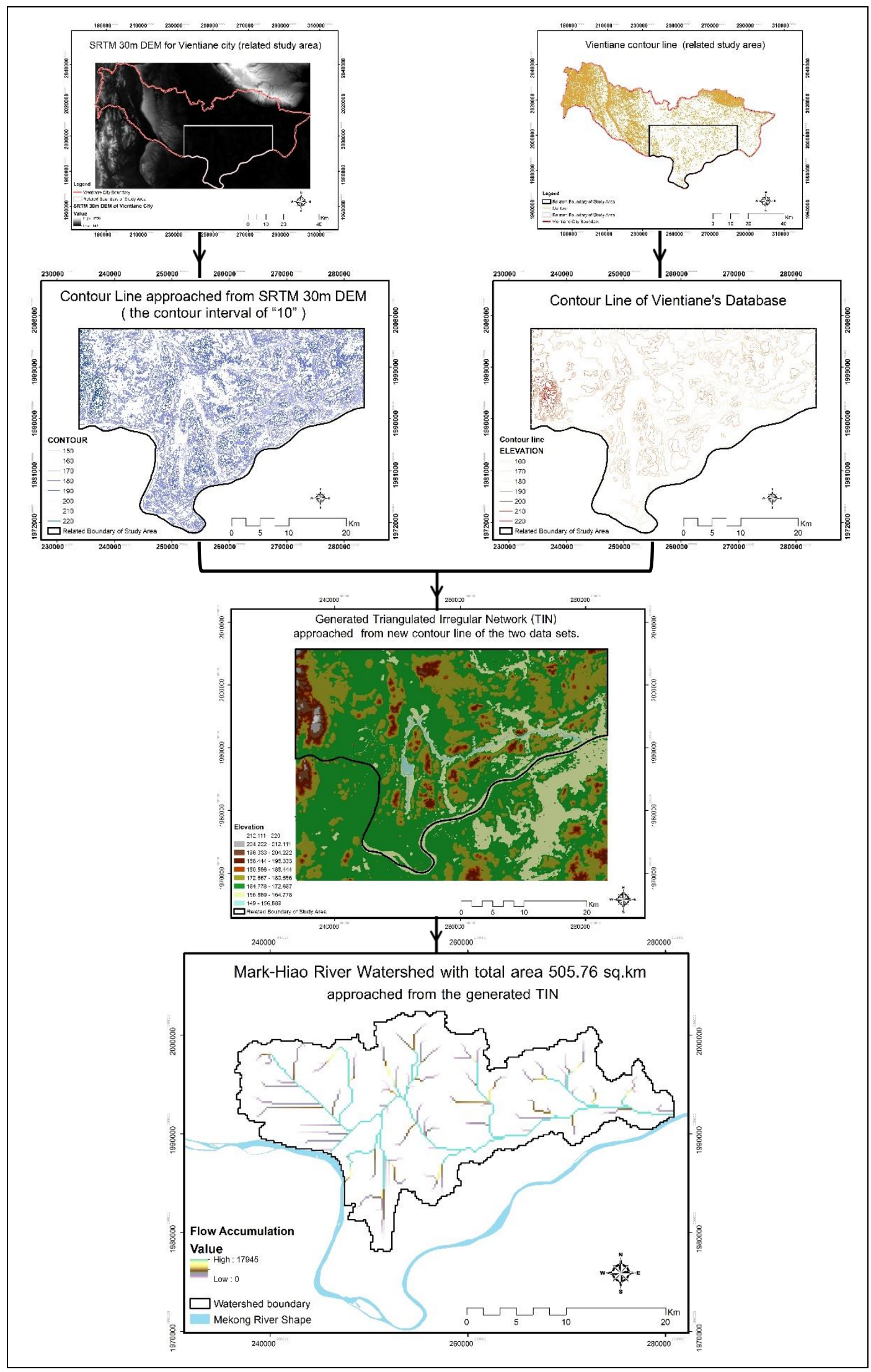

Figure 8. Watershed Generating Process of the Mark-Hiao River from Two Data Sets 


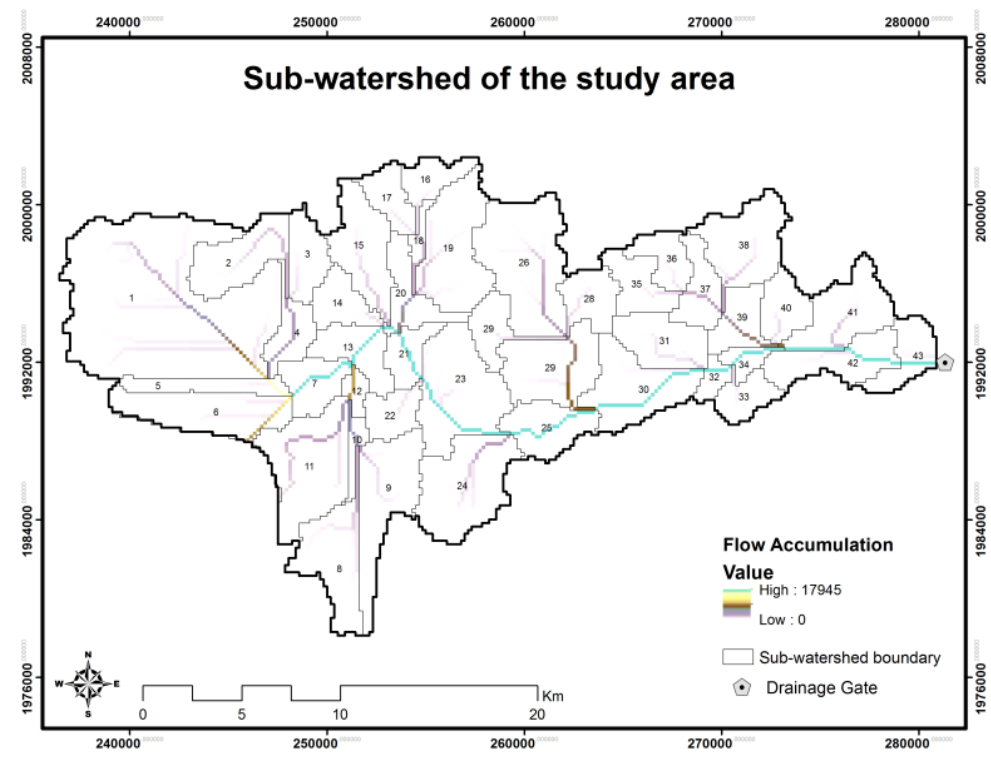

Figure 9. Automatic Sub Watershed Delineation for the Outlet Point Derived by ArcHydro Tool in ArcGIS

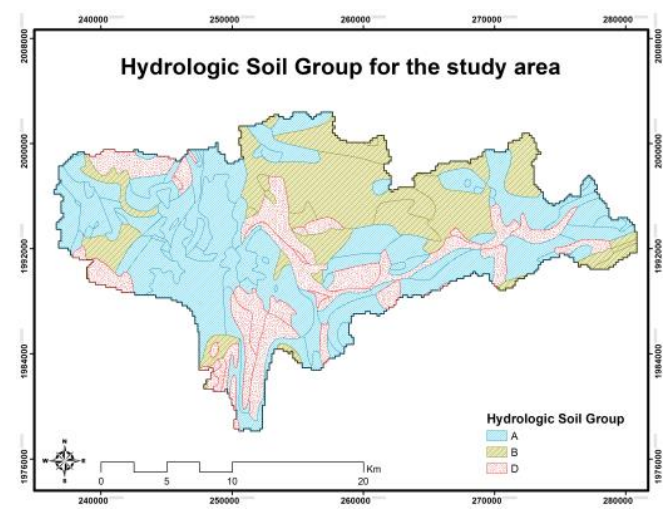

Figure 10. Hydrologic Soil Group Classification for the Study Area

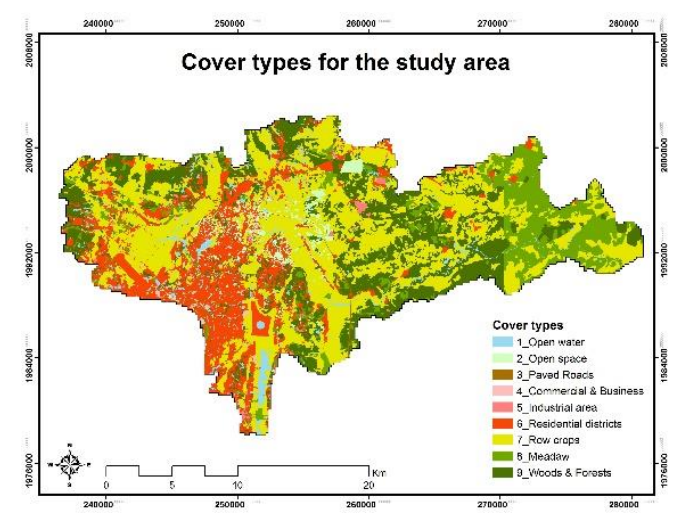

Figure 11. Cover Types Classification for the Study Area

Table 2. Hydrologic Soil-Cover Complexes and its $\mathrm{CN}$ values for the River Watershed of the Study Area

\begin{tabular}{|c|c|c|c|c|c|c|}
\hline $\begin{array}{l}\text { S- } \\
\text { LU }\end{array}$ & \multirow[t]{2}{*}{ Cover types } & \multirow{2}{*}{$\begin{array}{l}\text { Area } \\
\left(\mathrm{Km}^{2}\right)\end{array}$} & \multirow{2}{*}{$\begin{array}{l}\text { Area } \\
(\%)\end{array}$} & \multicolumn{3}{|c|}{$\begin{array}{l}\text { Curve number of ARC II } \\
\text { for HSG }\end{array}$} \\
\hline & & & & A & $\mathrm{B}$ & $\mathrm{D}$ \\
\hline 1 & Open Water body, lakes, ponds & 16.81 & 3.32 & 98 & 98 & 98 \\
\hline 2 & Open space (park, golf courses) & 12.54 & 2.48 & 49 & 69 & 84 \\
\hline 3 & Streets and Roads (Paved) & 5.66 & 1.12 & 98 & 98 & 98 \\
\hline 4 & Commercial and Business & 4.64 & 0.92 & 89 & 92 & 95 \\
\hline 5 & Industrial area & 4.08 & 0.81 & 81 & 88 & 93 \\
\hline 6 & Residential districts & 89.13 & 17.62 & 61 & 75 & 87 \\
\hline 7 & Row crops & 199.04 & 39.35 & 67 & 78 & 89 \\
\hline 8 & Meadow & 60.52 & 11.97 & 30 & 58 & 78 \\
\hline 9 & Woods and Forests & 113.35 & 22.41 & 30 & 55 & 77 \\
\hline & $\begin{array}{c}\text { Total: } \\
\end{array}$ & 505.76 & & & & \\
\hline
\end{tabular}




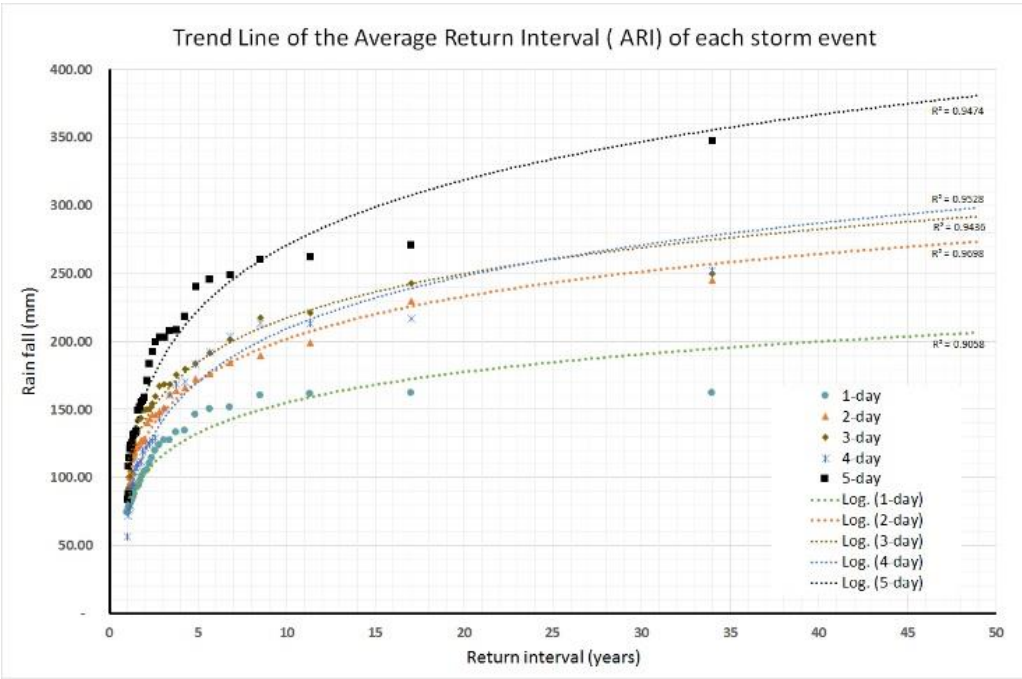

Figure 12. Trend Lines of Regression Analysis for 1- to 5-day Storm Durations, based on the Method of ARI, at Vientiane Rainfall Station

Table 3. Average Return Interval for Selected 1- to 5-day Storms Durations

\begin{tabular}{|c|c|c|c|c|c|}
\hline \multirow{2}{*}{$\begin{array}{c}\text { ARI } \\
\text { (years) }\end{array}$} & \multicolumn{5}{|c|}{ Duration of storm events } \\
\cline { 2 - 6 } & 1-day & 2-day & 3-day & 4-day & 5-day \\
\hline 25 & 185 & 243 & 260 & 261 & 334 \\
\hline
\end{tabular}

\subsection{Estimation of Direct Runoff from Storm Rainfall}

The direct runoff for the watershed was estimated by using the developed data mentioned above. Based on the Mark-Hiao River watershed maps generated, the runoff values were calculated by using the Weighted-Q method to get average runoff for whole area and for each sub-watershed as well. Figure 13 shows the average direct runoff from estimated storm rainfall (Figure12) in various rainfall amounts, for the whole river watershed. Table 4 shows the result of estimated direct runoff from selected storm duration categorized under the condition of ARCI, ARCII and ARC III.

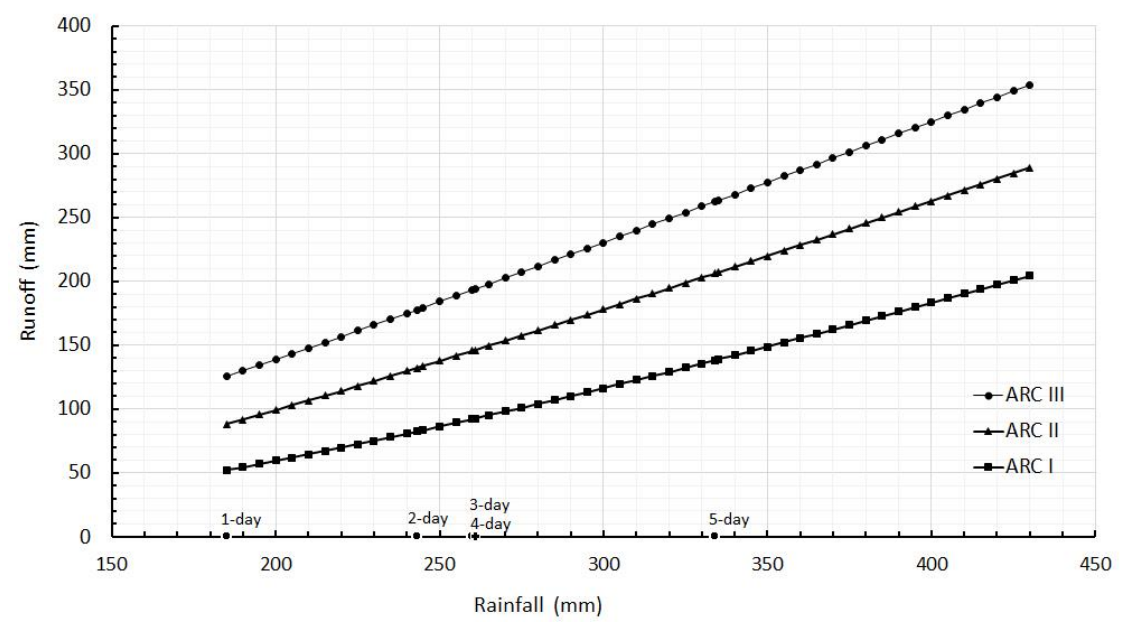

Figure 13. Average Direct Runoff for the Whole River Watershed Categorized under Three ARC Conditions 
Table 4. Estimation of Average Direct Runoff for the Study Area in the Three ARC Conditions

\begin{tabular}{|c|c|c|c|c|}
\hline \multicolumn{2}{|c|}{ ARI for 25years } & \multicolumn{3}{c|}{ Runoff (mm) } \\
\hline Storm events & Rainfall (mm) & ARC I & ARC II & ARC III \\
\hline 1-day & 185 & 52.17 & 88.18 & 125.45 \\
2-day & 243 & 82.43 & 132.01 & 177.68 \\
3-day & 260 & 92.18 & 145.46 & 193.31 \\
4-day & 261 & 92.77 & 146.25 & 194.23 \\
5-day & 334 & 138.23 & 206.30 & 262.44 \\
\hline
\end{tabular}

For modelling and mapping purposes, ArcHydro and spatial analysis tools of ArcGIS were used. The model output of calculating the curve number (Figure 14) and runoff estimation (Figure 15) in each pixel of hydrologic soil-cover complex were mapped for the river watershed. The three sets of $\mathrm{CN}$ values which have specific values based on each condition of ARC shown in Figure 14, were also applied to calculate runoff for the results of Table 4 by using the weighted-Q method.

Due to the flexibility and simplicity of using the weighted-Q method of NRCS runoff method, it is as valuable to estimate average direct runoff for small sub-basin. The average direct runoff was estimated for each of 43-subwatersheds in Mark-Hiao River watershed. The values of estimated direct runoff shown in Figure 16 were the result of input-estimated rainfall data for the duration of 5-day storm events over the 25-year period with a total rainfall amount of $334 \mathrm{~mm}$. As the result of the calculated average direct runoff, the high range runoff of about 200 to $230 \mathrm{~mm}$ covered the larger percentage of the whole watershed area especially in the upper zone as an urban area, while the lower range of about 124 to $180 \mathrm{~mm}$ was found near the outlet point of Mark-Hiao River.

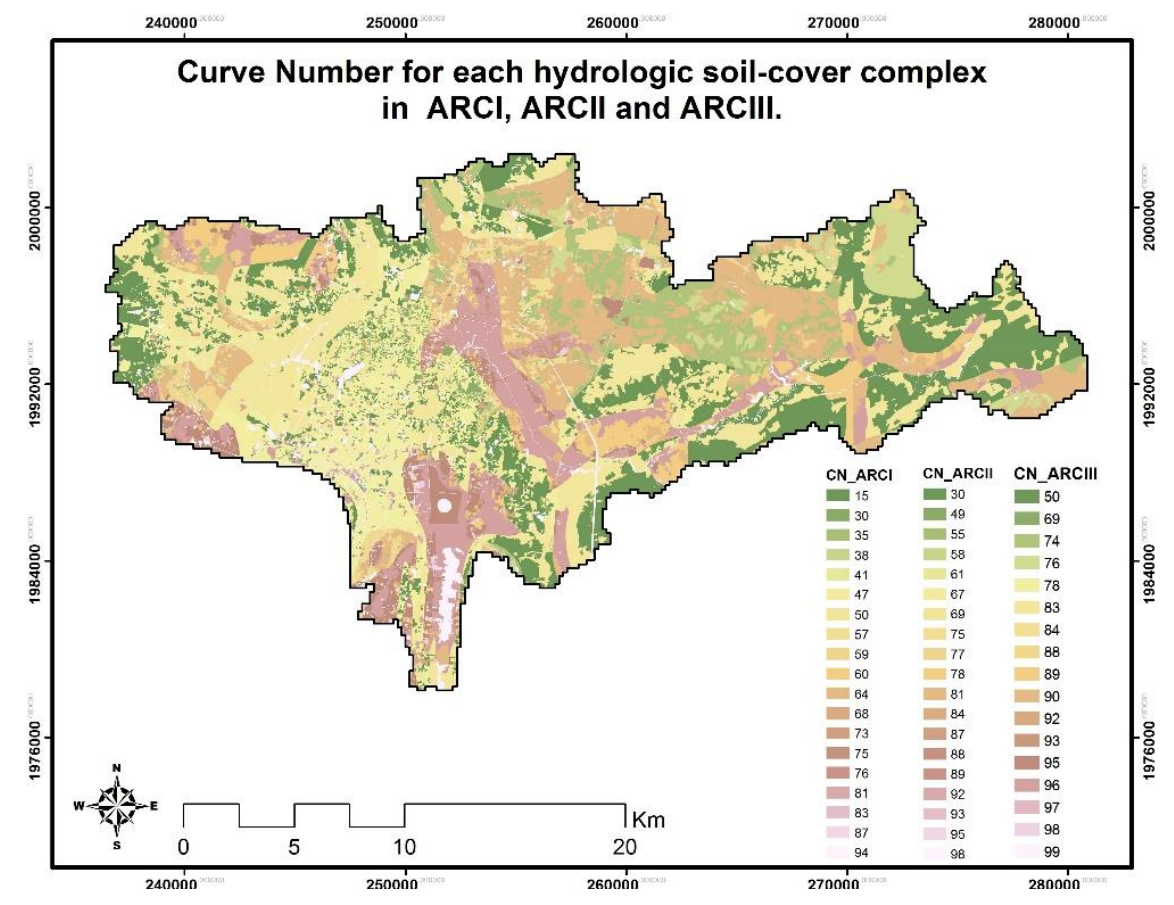

Figure 14. Curve Number (CN) Distribution Map for Mark-HiaoRiver Basins, for the ARC Conditions, in each Pixel of Hydrologic Soil-Cover Complex 


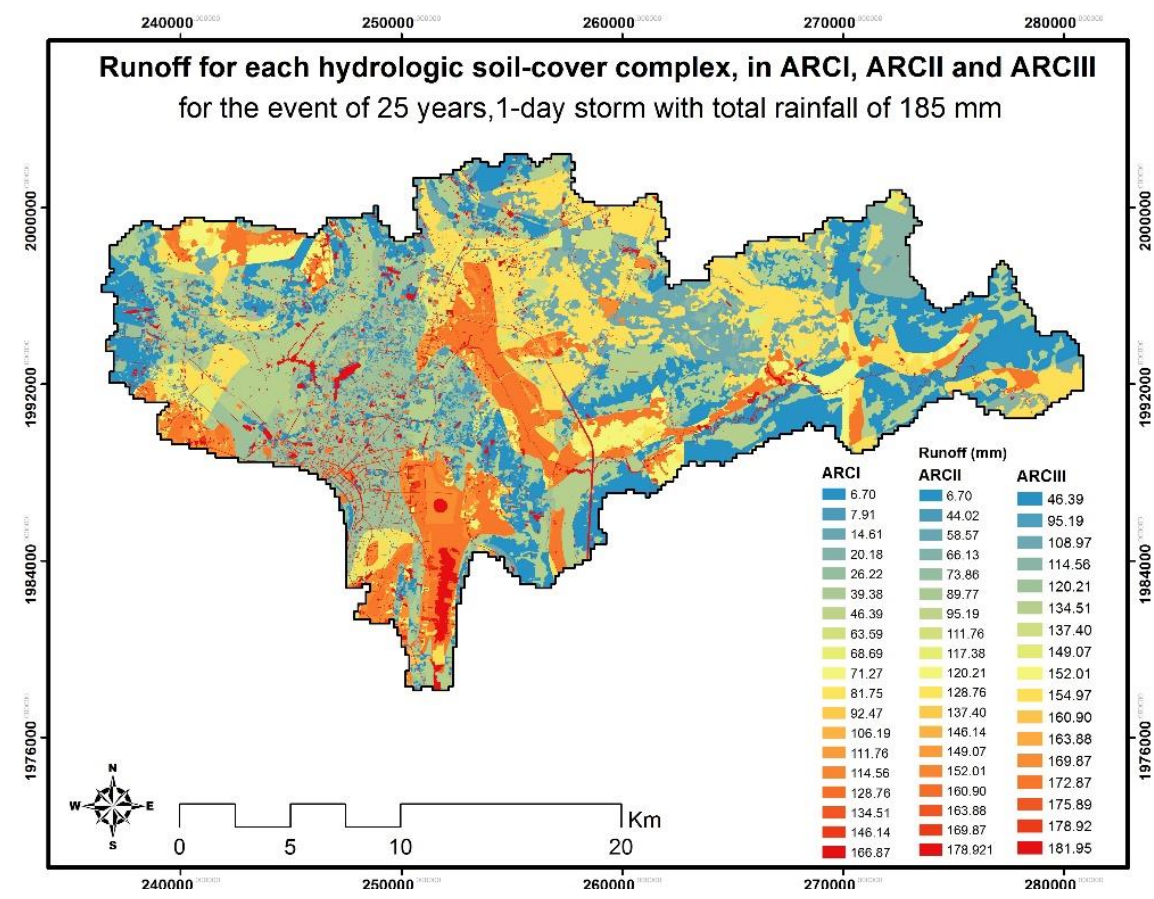

Figure 15. Estimated Runoff Distribution Map for Mark-HiaoRiver Basins, in the ARC Conditions, in each Pixel of Hydrologic Soil-Cover Complex with Specific Rainfall Condition

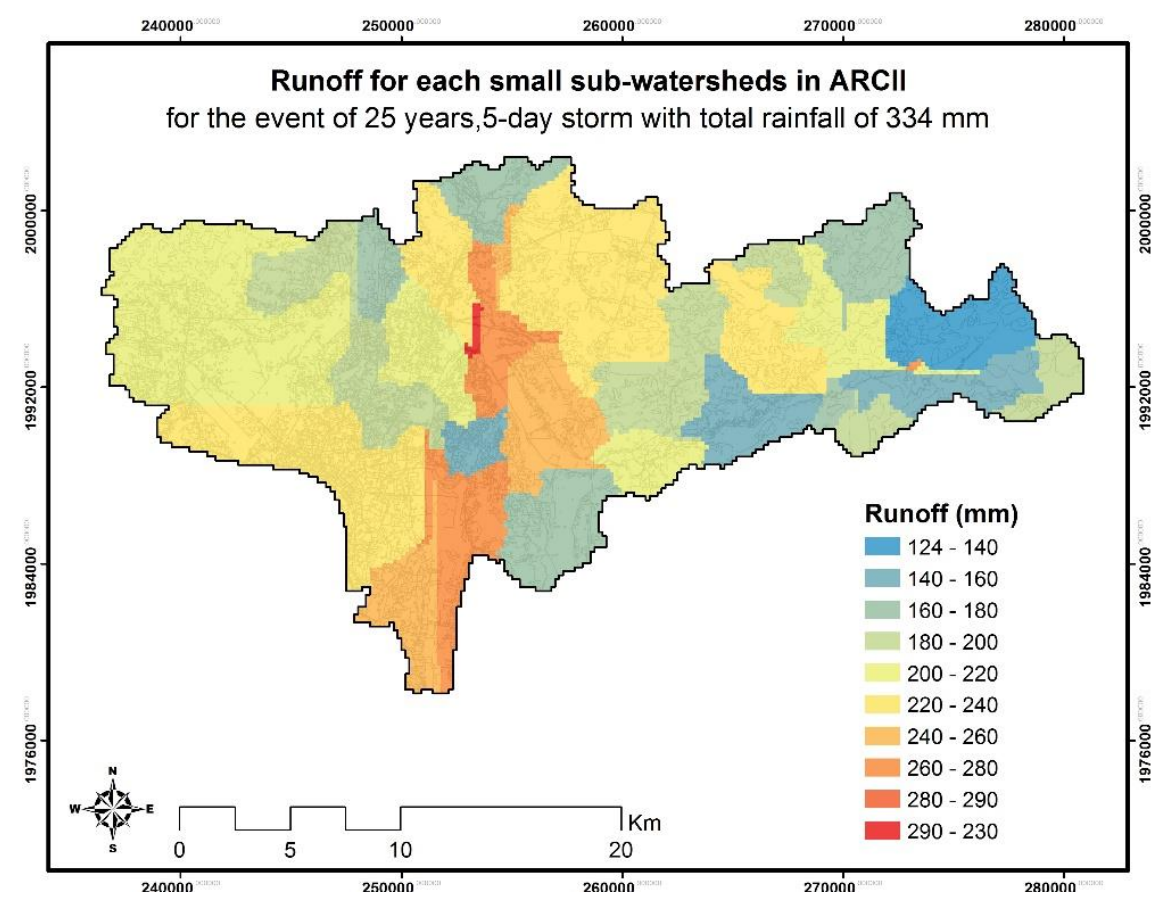

Figure 16. Estimated Runoff Distribution Map for Mark-Hiao River Basins, in each Sub-watershed with Specific Rainfall Conditions

\section{Conclusion}

This study aimed to understand the hydrologic conditions of Vientiane by determining runoff conditions in a river watershed by using the specific rainfall conditions. The estimation of direct runoff by using the NRCS method and ArcGIS-based data, was successfully done and it effectively achieved satisfactory results. This study demonstrated 
that the methodology for runoff estimation and spatial mapping could be applied in other river basins in Laos for watershed planning and management.

The interpolative technique through combining the downloaded data (SRTM 30m DEM) and the surveyed contour line dataset (Vientiane database) could represent current topography, especially slope conditions or elevation characteristics which are important sources for computing surface flow networks and their stream flow within a watershed area. Such flow networks are critical for modelling runoff accumulation as well as flood response [6]. In other words, the change of elevation or contour data directly affects the shape of a river watershed area and its sub-watersheds when during the delineation process. Therefore, using the interpolative technique is necessary to be considered carefully upon changing the shapes of obtained watershed area especially for watershed management strategy.

According to the simulation result of rainfall-runoff analysis, the hydrologic soil-cover complexes extracted from land use and soil layers are important parameters that could influence the runoff value. Increase of urbanization and reduction of other land cover types are major reasons for the increase in runoff co-efficient and runoff depth [8]. It is also important to note that the storm rainfall data used to test the runoff characteristic of the watershed in this study came from one station only which could not represent well the actual rainfall over the project area. Hence, more detailed input data including elevation, land use, soil and rainfall distribution data are always significant for obtaining more effective results concerning the runoff estimation.

\section{References}

[1] Virginia Department of Conservation and Recreation (VDCR). "Virginia Storm water Management Handbook", Second Edition, Department of Conservation \& Recreation, Richmond, vol. 2, (1999).

[2] M.E brahimian, A. Ainuddin Nuruddin,M. A. B.Mohd Soom \& A. M. Sood, "Application of NRCScurve number method for runoff estimation in a mountainous watershed". Caspian Journal of Environmental Science, vol. 10, no.1, (2011), pp.103-114.

[3] USDA-NRCS (United States Department of Agriculture- Natural Resources Conservation Service). "Estimated direct runoff from storm rainfall. National Engineering handbook Hydrology, Chapters 10, Part 630", Washington, DC, (2004).

[4] Manoj K. Jaina, Umesh C. Kothyari, Kittur G. Ranga Raju, "A GIS based distributed rainfall-runoff model”. Journal of Hydrology, vol. 299, nos. 1-2, (2004), pp.107-135.

[5] I. Elkhrachy, "Flash Flood Hazard Mapping Using Satellite Images and GIS Tools: A case study of Najran City, Kingdom of Saudi Arabia (KSA)". The Egyptian Journal of Remote Sensing and Space Sciences, vol. 18, no. 2, (2015), pp.261-278.

[6] A.Jarvis, J.Rubiano, A.Nelson, A. Farrow \& M. Mulligan, "Practical use of SRTM data in the tropics Comparisons with digital elevation models generated from cartographic data". International Center for Tropical Agricultural, Cali, Colombia, Working Document no. 198, (2004).

[7] Japan International Cooperation Agency (JICA), "The Project for Urban Development Master Plan Study in Vientiane Capital", Laos PDR, (2011).

[8] C.R. Suribabu. J. Bhaskar, "Evaluation of urban growth effects on surface runoff using SCS-CN method and Green-Ampt infiltration model”. Research Article. Earth Science Informatics., vol. 8, no. 3, (2015). pp. 609-626. 